\title{
Detection of Chlamydia trachomatis by the polymerase chain reaction in swabs and urine from men with non-gonococcal urethritis
}

\author{
H M Palmer, C B Gilroy, B J Thomas, P E Hay, C Gilchrist, D Taylor-Robinson
}

\begin{abstract}
A polymerase chain reaction (PCR) was developed for Chlamydia trachomatis in which a 380 base pair DNA fragment was amplified. Amplification occurred with the DNA from the 15 serovars but not with that from other Chlamydia spp or with DNA from a variety of other organisms. Chlamydial DNA $\left(10^{-16} \mathrm{~g}\right)$ could be detected and the PCR seemed to be able to detect single organisms. Urethral swabs were obtained from 37 men with acute non-gonococcal urethritis (NGU), $18(49 \%)$ of whom were positive for $C$ trachomatis by MicroTrak. As a result of clinical re-examinations 65 urethral swabs were available for analysis by the PCR. In comparison with MicroTrak, PCR had a sensitivity of $95 \%$, a specificity of $94 \%$, a positive predictive value of $86 \%$ and a negative predictive value of 98\%. The PCR was apparently less sensitive $(82 \%)$ in tests on urine samples. Overall, however, values of sensitivity and specificity of the PCR compared favourably with those of MicroTrak.

The PCR for $C$ trachomatis is likely to be a valuable technique for research, but problems of DNA contamination suggest that it should not be recommended for routine diagnosis.
\end{abstract}

Chlamydia trachomatis, an intracellular parasite of mucosal tissue, is a major cause of blindness in developing countries and is one of the most common agents of sexually transmitted disease in developed countries. In men $C$ trachomatis is a cause of non-gonococcal urethritis (NGU) and some cases of epididymitis and proctitis. ${ }^{1}$ There is also evidence that it is responsible for some cases of sexually acquired reactive arthritis, including Reiter's syndrome. ${ }^{23}$

In women $C$ trachomatis is a cause of the urethral syndrome and of mucopurulent cervicitis. Infection of the upper genital tract may result in pelvic inflammatory disease which, in turn, may lead to infertility or ectopic pregnancy. ${ }^{1}$ Carriage of $C$ trachomatis may also be asymptomatic in both women and men, ${ }^{14}$ providing a reservoir for infection. Clearly, $C$ trachomatis requires accurate detection to enable symptomatic cases to be treated appropriately, to determine the role of asymptomatic carriage in disease epidemiology, and to confirm its association or otherwise in disease where its role is as yet unclear.

In addition to culture, there are numerous other ways of detecting $C$ trachomatis based on immunological or molecular methods. ${ }^{5}$ The target is either the major outer membrane protein (MOMP) of the chlamydial elementary body (EB) as this is particularly conserved, or the lipopolysaccharide. The former is commonly detected by direct immunofluorescence tests using monoclonal antibodies (for example, MicroTrak, Syva), and the latter by enzyme immunoassays (for example, IDEIA, Novo Nordisk). The comparative performance of such assays has been reported extensively ${ }^{6}$ and compared to culture, they are faster and simpler. There are also disadvantages, however: MicroTrak requires skilled interpretation and, therefore, the reliability of results may vary among laboratories. Furthermore, the number of samples that can be processed each day is limited. Immunoassays have unsatisfactory predictive positive and negative values in populations with a low prevalence of chlamydial infection.

Molecular methods of detection using DNA probes, ${ }^{7-10}$ some with non-radioactive labels (PACE, Genprobe), are available. This approach is less sensitive, however, than some of the other methods. ${ }^{5}$ The polymerase chain reaction (PCR) has recently been developed to produce more sensitive DNA probes ${ }^{112}$ and used directly to detect $C$ trachomatis..$^{1314}$ This has considerable potential, exemplified by the sensitivity of PCR in detecting other organisms-namely, cytomegalovirus, ${ }^{15}$ human Blymphotropic virus, ${ }^{16}$ hepatitis $B$ virus, ${ }^{17}$ human immunodeficiency virus (HIV), ${ }^{18}$ human papillomavirus (HPV), ${ }^{19}$ Escherichia coli, ${ }^{20}$ Mycoplasma genitalium, ${ }^{21} M$ pneumonia $^{22}$ and Treponema pallidum. ${ }^{23}$

In this study we developed a PCR for $C$ trachomatis, and using urethral swabs and urines from patients with acute NGU, we compared its performance with that of MicroTrak.

\section{Methods}

Chlamydia trachomatis (15 serovars), $C$ psittaci (bovine strain), and $C$ pneumoniae (TWAR strain), grown in chick embryos or McCoy cell cultures by standard methods, ${ }^{24}$ were purified by differential centrifugation using Renografin. ${ }^{25}$ Other bacteria obtained from clinical
Correspondence to: Dr H M Palmer Accepted for publication 21 November 1990

carriage in disease


isolates were cultured using standard procedures. These were: Campylobacter sp, Gardnerella vaginalis, Haemophilus ducreyi, Lactobacillus acidophilus, Mobiluncus sp, Mycoplasma genitalium, $M$ hominis, Neisseria gonorrhoeae, Salmonella enteritidis, $S$ typhimurium, Shigella flexneri, $S$ sonnei, Staphylococcus aureus, $S$ epidermidis, Streptococcus faecalis and Ureaplasma urealyticum. An isolate of Candida albicans was also cultured. DNA from some other organisms was received from colleagues as follows: $\mathrm{HPV}$ and $\mathrm{HIV}$ (from $\mathrm{Mr} \mathrm{M}$ Botcherby), $T$ pallidum (from Dr P Hay), and Trichomonas vaginalis (from Dr A Yule). Clinical specimens were obtained from men with acute NGU attending the genitourinary medicine clinic (Jefferiss Wing) of St Mary's Hospital. On presentation, a urine sample (about the first $20 \mathrm{ml}$ ) and two urethral swabs (one to be stored and one for analysis by MicroTrak and the PCR) were taken; similar samples were taken at weekly follow up visits. Men were excluded from the study if culture for $N$ gonorrhoeae proved positive.

PROCESSING OF CLINICAL SPECIMENS

MicroTrak and the PCR were used to detect $C$ trachomatis from a single urethral swab. Swabs were rolled on MicroTrak slides and then expressed in $400 \mu \mathrm{l}$ of sterile distilled water, which was stored at $-20^{\circ} \mathrm{C}$ before analysis by the PCR. Urine specimens were divided into three aliquots which were centrifuged at $1600 \times g$ for 30 minutes. Two of the deposits were analysed for the presence of $C$ trachomatis by MicroTrak and the PCR (as detailed below), respectively, and the third stored at $-70^{\circ} \mathrm{C}$.

EXAMINATION OF SAMPLES BY MICROTRAK

Urine deposits were resuspended in $100 \mu \mathrm{l}$ of distilled water, and $10 \mu \mathrm{l}$ of each suspension were allowed to dry on a MicroTrak slide. These dried deposits and urethral smears on slides were treated, and the numbers of fluorescing elementary bodies scored, as des- cribed previously. ${ }^{24}$ Samples containing one or more elementary bodies were recorded as positive.

PREPARATION OF SAMPLES FOR THE PCR

DNA was extracted from cultured microorganisms, uninfected McCoy cells, and human buccal cells by standard methods ${ }^{26}$ and $10 \mathrm{ng}$ aliquots were used for the PCR. DNA from urine deposits was extracted similarly, except that the DNA was dissolved in $50 \mu \mathrm{l}$ of sterile distilled water and used directly for the PCR. A maximum of five samples and a control ( $400 \mu \mathrm{l}$ of sterile distilled water) were processed together at any one time. Gloves were changed between the handling of each specimen to avoid contamination by "carry over" of DNA. Distilled water containing material from a urethral swab was centrifuged (10 minutes at $11000 \times g)$ and the deposit resuspended in 50 $\mu l$ of the supernatant and transferred to a $0.5 \mathrm{ml}$ microcentrifuge tube. This fluid was covered with $50 \mu \mathrm{l}$ of mineral oil and boiled for 10 minutes before DNA amplification by the PCR.

DNA AMPLIFICATION BY THE PCR

Oligonucleotide primers were designed to amplify a fragment within the conserved region of a MOMP gene of $C$ trachomatis (fig 1). Target DNA was amplified first using $1 \mu \mathrm{g}$ of each of the primers HP1 and HP2 in a $100 \mu 1$ volume containing $2 \mathrm{mM} \mathrm{MgCl}_{2}, 50 \mathrm{mM} \mathrm{KCl}$, $10 \mathrm{mM}$ TRIS- $\mathrm{HCl}$ (pH 8.4), $0.01 \%$ gelatin, $0.05 \%$ Tween-20 (Sigma), $0.2 \mathrm{mM}$ dNTPs (Pharmacia) and 2.5 units Amplitaq DNA polymerase (Perkin Elmer Cetus). The optimum conditions for the reaction were as follows: 1.5 minutes annealing at $45^{\circ} \mathrm{C} ; 3.0$ minutes extension at $72^{\circ} \mathrm{C}$, and 1.5 minutes denaturation at $94^{\circ} \mathrm{C}$ for 35 cycles, with the extension time increased to 9.9 minutes during the final cycle. The reaction product $(2 \mu \mathrm{l})$ was amplified for a second time using $1 \mu \mathrm{g}$ each of primers HP2 and HP3 with all other conditions remaining the same.
Name of primer

HP1

HP2

HP3

HP4

HP5
Site on gene

$1-26$

TAT ACA AAA ATG GCT CTC TGC TTT AT

126

512-537

158-177

TTG CCA GAC AAT CCT CAG GC

$138-157$

TCG ATT AAG GCT GCT TTT AC

448-467

1

100

200

300

400

500

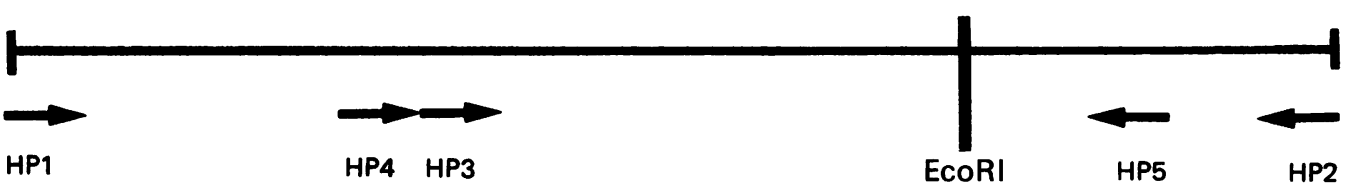

Figure 1 Sequence and arrangement of oligonucleotide primers and probe, and the position of the EcoRI site on the $C$ trachomatis MOMP gene. 


\section{ANALYSIS OF AMPLIFIED DNA}

Amplified product $(20 \mu \mathrm{l})$ was analysed by electrophoresis in a $2 \%$ agarose gel, using standard methods. ${ }^{27} \mathrm{~A}$ further $2 \mu \mathrm{l}$ was digested with $E c o R I$ in a total volume of $20 \mu \mathrm{l}$ and analysed by electrophoresis using a $1 \%$ agarose gel. Finally, the product was blotted and hybridised with $1 \mathrm{ng}$ of a ${ }^{32} \mathrm{P}$-end labelled oligonucleotide probe (fig 1).

\section{Results}

SPECIFICITY OF THE PCR

A 537 base pair DNA fragment was amplified from $C$ trachomatis (serovar $\mathrm{L}_{2}$ ) with primers HP1 and HP2 (fig 2). Reamplification of this product with primers $\mathrm{HP} 2$ and $\mathrm{HP} 3$ produced a 380 base pair fragment. Endonuclease digestion of the larger product with EcoRI gave two fragments of 393 and 144 base pairs (fig 2) and these hybridised to the oligonucleotide probe. Target DNA from the remaining 14 serovars of $C$ trachomatis using the two sets of primers as before gave a final product size of 380 base pairs (fig 3). No amplification occurred with DNA from any of the other organisms tested.

Figure 2 Electrophoresis of first and second PCR products and confirmation of their identity by enzyme cleavage. PCR product using HP1 and HP2 and subsequently digested with EcoRI (lane 1), the same product undigested (lane 2), PCR product using primers $H P 2$ and $H P 3$ (lane 3), HaeIII digest of QX174 RF DNA with fragment sizes indicated (lane 4).

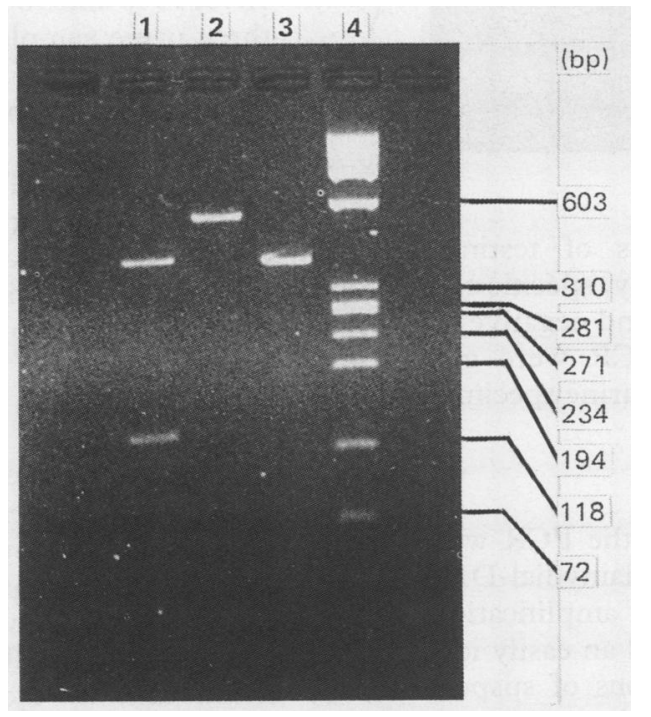

SENSITIVITY OF THE PCR

Serial 10-fold dilutions of $C$ trachomatis $\left(\mathrm{L}_{2}\right.$ serovar) DNA (initially quantified by ultraviolet spectrophotometry) were used to determine the sensitivity of the PCR; $10^{-16} \mathrm{~g}$ could be detected (fig 4). Suspensions of elementary bodies were also examined by MicroTrak, and a suspension containing 100 elementary bodies $/ 10 \mu \mathrm{l}$ aliquot was further diluted 100-fold. DNA was detected by the PCR in eight of 10 aliquots that were thus calculated to contain one elementary body (fig 5).

\section{EXAMINATION OF CLINICAL SPECIMENS}

Urethral swabs were obtained from 37 patients at their first visit. Of these, $18(49 \%)$ were positive for $C$ trachomatis by MicroTrak. Most patients returned at least once for examination. In all, 65 urethral swabs were available for analysis by MicroTrak and the PCR. Table 1 shows that there was good correlation between the results of the two procedures: of the 19 specimens positive by MicroTrak, four contained fewer than 10 elementary bodies, of which three were detected by the PCR. Thirty six of the patients provided a sample of urine at their first visit. Of these, $16(44 \%)$ were positive for $C$ trachomatis by MicroTrak. Including samples from follow up visits, 63 urines were available for analysis. All of these were tested by MicroTrak and the PCR and the results were in close agreement (table 1); of the 17 specimens positive by MicroTrak, eight contained fewer than 10 elementary bodies, of which six were detected by the PCR. C trachomatis was detected by both techniques in urethral and urine specimens from one patient after treatment and three weeks after the first clinic visit, and its occurrence was presumed to be due to a newly acquired infection. Otherwise, $C$ trachomatis was not detected by MicroTrak in specimens from patients on return visits and was detected only once by the PCR. Two specimens were excluded from the analysis because the controls in the PCR suggested that they were falsely positive.
Figure 3 Electrophoresis of amplified DNA from 14 $C$ trachomatis serovars: $A$ to $K, L_{1}$ and $L_{3}$ (lanes $1-$ 14); no product from other sources of target DNA-N gonorrhoeae, $C$ psittaci, $C$ pneumoniae, and human buccal cells (lanes 15-18 respectively); positive control-C trachomatis serovar $L_{2}$ (lane 19); negative control (sterile distilled water) prepared with the other samples (lane 20), and $0 X 174 R F$ DNA (lane 21).

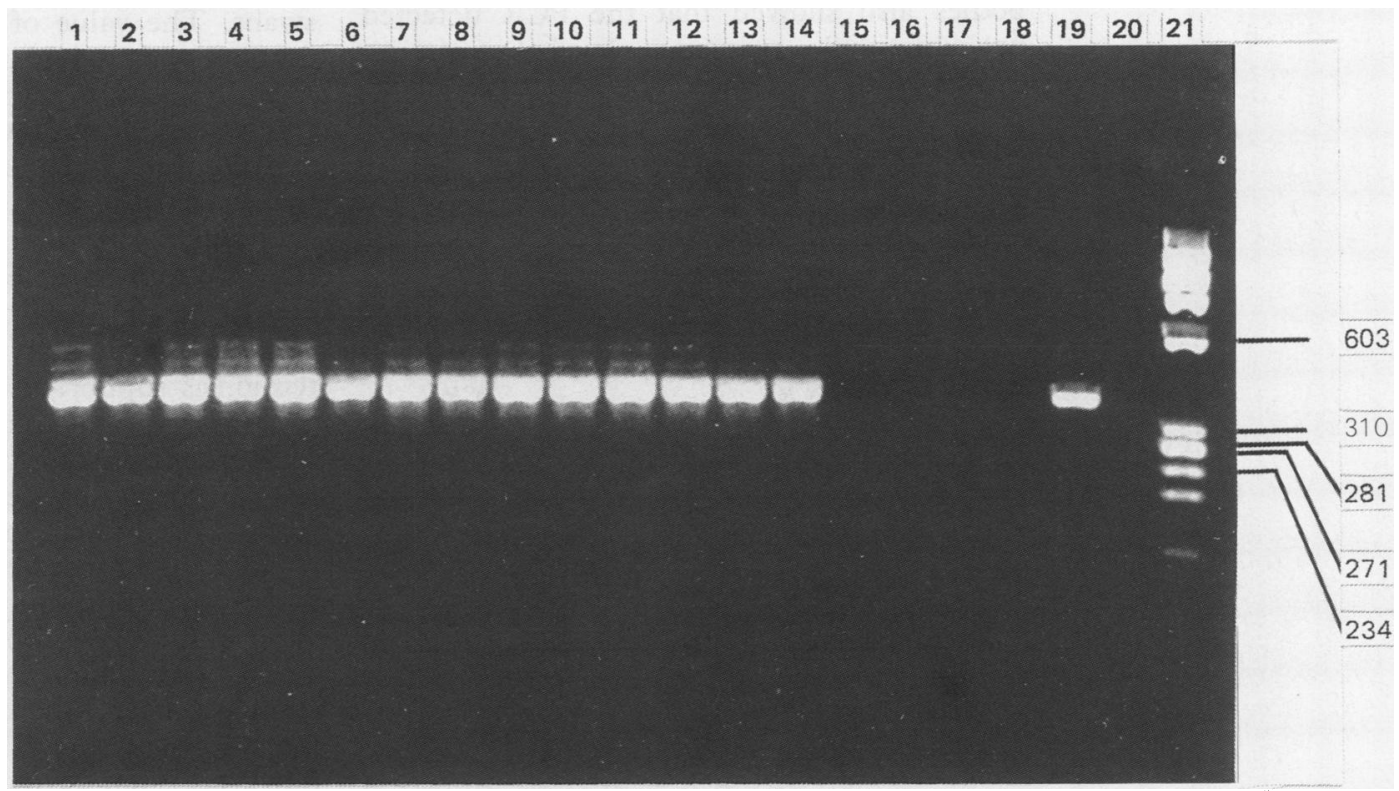


Figure 4 Serial dilutions of C trachomatis DNA $\left(10^{-12}\right.$ to $\left.10^{-16} \mathrm{~g}\right)$ after amplification with primers $H P 1$ and HP2 (lanes 1 5), and after

reamplification with primers $H P 2$ and $H P 3$

(lanes 7-11); negative controls (sterile distilled water) prepared together with the other samples (lanes 6 and 12), and -X174 RF DNA (lane 13).

Figure 5 Amplified DNA from samples calculated to contain single elementary bodies (lanes 1-10), positive control: $C$ trachomatis serovar $L_{2}$ (lane 11); negative control (sterile distilled water) prepared with the other samples (lane 12), and $0 X 174 R F D N A$ (lane 13).
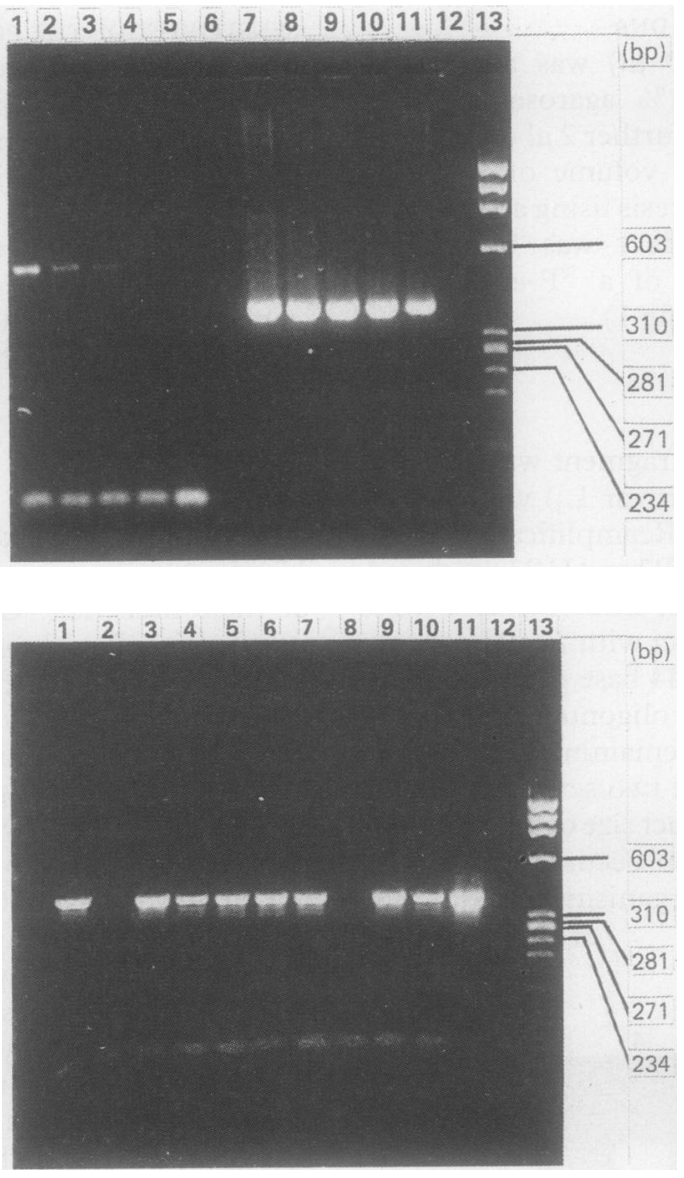

Based on the results of testing clinical specimens, the sensitivity, specificity, positive predictive value (PPV) and negative predictive value (NPV) of the PCR were greater for urethral swabs than for urine specimens (table 2).

\section{Discussion}

Optimal conditions for the PCR were determined using purified chlamydial DNA. After two successive rounds of amplification, $10^{-16} \mathrm{~g}$ of target DNA produced an easily identifiable product. Testing dilutions of suspensions of known numbers of chlamydial elementary bodies also showed that the PCK detected probably single organisms, a level of sensitivity similar to that of MicroTrak. Tests on all 15

Table 1 Results of testing urethral swabs and urines by PCR compared with MicroTrak

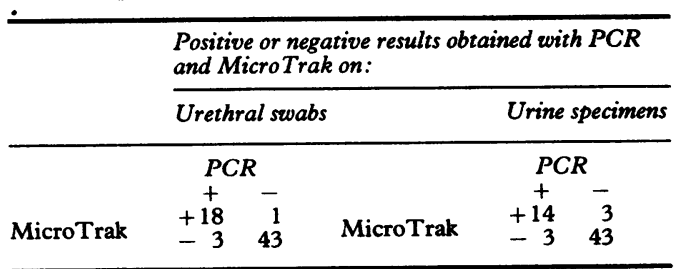

Table 2 Sensitivity, specificity, PPV and NPV of PCR compared with MicroTrak

\begin{tabular}{lllll}
\hline Specimen & Sensitivity & Specificity & PPV & NPV \\
\hline Urethral swab & $95 \%$ & $94 \%$ & $86 \%$ & $98 \%$ \\
Urine & $82 \%$ & $94 \%$ & $82 \%$ & $94 \%$ \\
\hline
\end{tabular}

serovars of $C$ trachomatis, other Chlamydia spp, genital microflora, and agents associated with reactive arthritis showed that the PCR was species specific. As all serovars were recognised, the PCR could prove a useful detection system for both the ocular and genital spectra of chlamydial diseases.

Further evaluation of the PCR using specimens from men with acute NGU suggested that, overall, this method of detection was a little less effective than MicroTrak. Several observations indicate, however, that there were a few false negative results for MicroTrak, which was used as the "gold standard". These led to an underestimation of the specificity of the PCR. Contamination would seem to be the most likely explanation of a positive result for one of the specimens because this was taken after antibiotic treatment. The other two patients whose urethral swabs were found to be chlamydia negative by MicroTrak but positive by the PCR, however, were confirmed as chlamydia positive by virtue of a positive MicroTrak test of the urine sample. If these results are included as true positive results, the sensitivity, specificity, PPV and NPV of the PCR in tests on urethral swabs would be $95 \%$, $98 \%, 95 \%$ and $98 \%$, respectively. In addition, three urine samples, from patients who were chlamydia negative in the urethra, were positive only by the PCR. This may mean that the PCR detected elementary bodies that were missed by MicroTrak, or may reflect contamination during processing. The inclusion of control samples at every stage which were consistently negative suggests that contamination by "carry over" is unlikely. Sporadic contamination of samples by aerosol is a common problem when using the PCR as a detection system ${ }^{28}$ and cannot be discounted. All three urine specimens positive only by the PCR, however, were from patients during their first visit so that such results were feasible. If these were truly positive both the specificity and PPV of the PCR would be increased to $100 \%$, and these variables of detection of $C$ trachomatis by the PCR using urines would compare favourably to detection using urethral swabs. The value of testing urine as a noninvasive approach to detecting $C$ trachomatis in men has been reported elsewhere ${ }^{29}$ and emphasised by our own observations. ${ }^{30}$

Two swabs and a urine sample were taken at the same visit and each urine sample was subdivided into three. Therefore, when there were only small numbers of elementary bodies, one or more of the samples may not have contained elementary bodies at all. This contention is supported by the fact that three of four samples that were falsely negative by the PCR corresponded to samples that contained fewer than 10 elementary bodies by MicroTrak. Therefore, if a sample was not subdivided but used in a single test, fewer false negative results would be likely and the sensitivity and NPV of the PCR would be greater.

A new technique can be evaluated only by comparison with an existing "gold" standardin this case MicroTrak. Use of the latter, however, is not devoid of errors and when this 
is taken into consideration the sensitivity and specificity of the PCR compare very favourably with those of MicroTrak. Whether the occasional positive result unique to the PCR is due to sporadic contamination or is truly positive can be established only by testing duplicate samples, such contamination being unlikely to occur twice. In this study one third of the samples were controls which were included to distinguish between true positive results and those produced by "carry over" contamination. This degree of caution would not be feasible on a routine basis for clinical diagnosis and, therefore, the PCR is not recommended for this purpose. Furthermore, although the PCR is highly sensitive, capable of detecting small numbers of elementary bodies, it is not more so than MicroTrak and its use is unlikely to increase detection of chlamydial prevalence: it has not done so in this study of men with NGU. Nevertheless, the PCR promises to be a useful alternative to MicroTrak for research purposes where measures to prevent contamination are strictly adhered to and duplicate tests are carried out where necessary.

1 Taylor-Robinson D, Munday PE. Chlamydial infections. In: Oriel JD, Waugh M, eds. Anglo-Scandinavian conference on sexually transmitted diseases. London: Royal ference on sexually transmitted diseases. Lon

2 Keat A, Thomas BJ, Taylor-Robinson D. Chlamydial infection and arthritis. Br Med Bull 1983;39:168-74.

3 Keat A, Thomas B, Dixey J, Osborn M, Sonnex C, TaylorRobinson D. Chlamydia trachomatis and reactive arthritis-the missing link. Lancet 1987; i:72-4.

4 Stamm WE, Koutsky LA, Benedetti JK, Jourden JL, Brunham RC, Holmes KK. Chlamydia trachomatis urethral infections in men. Prevalence factors and clinical manifestations. Ann Intern Med 1984;100:47-51.

5 Ridgway GL, Taylor-Robinson D. Human chlamydia infections: which laboratory test? J Clin Pathol 1991;44: $1-5$.

6 Barnes RC. Laboratory diagnosis of human chlamydial infections. Clin Microbiol Rev 1989;2:119-36.

7 Peterson EM, Oda R, Alexander R, Greenwood JR, de la Maza LM. Molecular techniques for the detection of Maza LM. Molecular techniques for the detection of
Chlamydia trachomatis. JClin Microbiol 1989;27:2359-63.

8 Horn JE, Quinn T, Hammer M, Palmer L, Falkow S. Use of nucleic acid probes for the detection of sexually transmitted infectious agents. Diagn Microbiol Infect Dis 1986, 4:101S-9S.

9 Hyypiä T, Jalava A, Larsen SH, Terho P, Hukkanen V. Detection of Chlamydia trachomatis in clinical specimens by nucleic acid spot hybridisation. J Gen Microbiol 1985;131:975-8.

10 Pao CC, Lin S, Yang T, Soong Y, Lee P, Lin J. Deoxyribonucleic acid hybridisation analysis for the detection of urogenital Chlamydia trachomatis infections in women. Am J Obstet Gynecol 1987;156:195-9.
11 Dean D, Pant CR, O'Hanley P. Improved sensitivity of a modified polymerase chain reaction amplified DNA probe in comparison with serial tissue culture passage for detection of Chlamydia trachomatis in conjunctival specimens from Nepal. Diagn Microbiol Infect Dis 1989; 12:133-7.

12 Pollard DR, Tyler SD, Ng C-W, Rozee KR. A polymerase chain reaction (PCR) protocol for the specific detection of Chlamydia spp. Mol Cell Probes 1989;3:383-9.

13 Dutilh B, Bébéar C, Rodriguez P, Vekris A, Bonnet J, Garret $M$. Specificamplification of a DNA sequence common to all Chlamydia trachomatis serovars using the polymerase chain reaction. Res Microbiol 1989;140:7-16.

14 Griffais R, Thibon M. Detection of Chlamydia trachomatis by the polymerase chain reaction. Res Microbiol 1989; 140:139-41.

15 Demmler GJ, Buffone GJ, Schimbor CM, May RA. Detection of cytomegalovirus in urine from newborns by using polymerase chain reaction DNA amplification. J Infect Dis 1988;158:1177-84.

16 Buchbinder A, Iosephs SF, Ablashi D, et al. Polymerase chain reaction amplification and in situ hybridisation for the detection of human B-lymphotropic virus. J Virol Methods 1988;21:191-7.

17 Kaneko S, Miller RH, Feinstone SM, et al. Detection of serum hepatitis B virus DNA in patients with chronic hepatitis using the polymerase chain reaction assay. Proc Natl Acad Sci USA 1989;86:312-6.

18 Kwok S, Mack DH, Mullis KB, et al. Identification of human immunodeficiency virus sequences by using in vitro enzymatic amplification and oligomer cleavage detection. $J$ Virol 1987;61:1690-4.

19 Shibata DK, Arnheim N, Martin WJ. Detection of human papilloma virus in paraffin-embedded tissue using the polymerase chain reaction. $J$ Exp Med 1988;167:225-30.

20 Olive MD. Detection of enterotoxigenic Escherichia col after polymerase chain reaction amplification with a thermostable DNA polymerase. J Clin Microbio 1989;27:261-5.

21 Palmer HM, Gilroy CB, Furr PM, Taylor-Robinson D. Development and evaluation of the polymerase chain reaction to detect Mycoplasma genitalium. FEMS Microbiol Letts 1991;77:199-203.

22 Bernet C, Garret $M$, de Barbeyrac B, Bebear C, Bonnet J. Detection of Mycoplasma pneumoniae by using the polymerase chain reaction. J Clin Microbiol 1989;27: polymerast

23 Hay PE, Clarke JR, Strugnell RA, Taylor-Robinson D, Goldmeier $D$. Use of the polymerase chain reaction to detect DNA sequences specific to pathogenic treponemes in cerebrospinal fluid. FEMS Microbiol Letts 1990;68 233-8.

24 Thomas BJ, Evans RT, Hawkins DA, Taylor-Robinson D Sensitivity of detecting Chlamydia trachomatis elementary bodies in smears by use of a fluorescein labelled monoclonal antibody: comparison with conventional chlamydial isolation. J Clin Pathol 1984;37:812-6.

25 Howard L, Orenstein NS, King NW. Purification on renografin density gradients of Chlamydia trachomatis grown in the yolk sac of eggs. Appl Microbiol 1974;27:102-6.

26 Wilson K. In: Ausubel FM, ed. Current protocols in molecular biology 1987-1988. New York: John Wiley \& Sons, 1987.

27 Maniatis T, Frisch EF, Sambrook J. Molecular cloning (a laboratory manual). New York: Cold Spring Harbor Laboratories, 1982 .

28 Kwok S, Higuchi R. Avoiding false positives with PCR Nature 1989;339:237-8.

29 Paul ID, Caul ED. Evaluation of three Chlamydia trachomatis immunoassays with an unbiased, non-invasive clinical sample. J Clin Microbiol 1990;28:220-2.

30 Hay PE, Thomas BJ, Gilchrist C, Palmer HM, Gilroy CB, Taylor-Robinson $\mathrm{D}$. The value of urine samples from men with non-gonococcal urethritis for the detection of Chlamydia trachomatis. Genitourin Med (In Press). 